\title{
Mosaic Organization of Orthologous Sequences in Grass Genomes
}

\author{
Rentao Song, Victor Llaca, ${ }^{1}$ and Joachim Messing ${ }^{2}$ \\ Waksman Institute, Rutgers, The State University of New Jersey, Piscataway, New Jersey 08854-8020, USA
}

\begin{abstract}
Although comparative genetic mapping studies show extensive genome conservation among grasses, recent data provide many exceptions to gene collinearity at the DNA sequence level. Rice, sorghum, and maize are closely related grass species, once sharing a common ancestor. Because they diverged at different times during evolution, they provide an excellent model to investigate sequence divergence. We isolated, sequenced, and compared orthologous regions from two rice subspecies, sorghum, and maize to investigate the nature of their sequence differences. This study represents the most extensive sequence comparison among grasses, including the largest contiguous genomic sequences from sorghum $(425 \mathrm{~kb})$ and maize ( $435 \mathrm{~kb})$ to date. Our results reveal a mosaic organization of the orthologous regions, with conserved sequences interspersed with nonconserved sequences. Gene amplification, gene movement, and retrotransposition account for the majority of the nonconserved sequences. Our analysis also shows that gene amplification is frequently linked with gene movement. Analyzing an additional $2.9 \mathrm{Mb}$ of genomic sequence from rice not only corroborates our observations, but also suggests that a significant portion of grass genomes may consist of paralogous sequences derived from gene amplification. We propose that sequence divergence started from hotspots along chromosomes and expanded by accumulating small-scale genomic changes during evolution.

[GenBank Accession Numbers: Rice (Oryza sativa L. ssp. japonica) php200725 region: AF119222; rice (Oryza sativa L. ssp. indica) php200725 region: AF128457; sorghum (Sorghum bicolor) php200725 region: AF114171, AF527807, AF727808, AF527809; maize (Zea mays) php200725 region: AF090447, AF528565; rice chromosome 10 region (2.9 Mb): AC073391, AC087549, AC027657, AC087547, AC027658, AC087546, AC027659, AC087550, AC025905, AC087545, AF229187, AC027660, AC087544, AC027661, AC027662, AC087543, AC073392, AC087542, ACO25906, AC073393, AC025907.]
\end{abstract}

All grasses belong to a single family, Gramineae, that contains $\sim 10,000$ species, and originated $\sim 65$ million years ago (mya; Kellogg 2000). Gramineae family members include important cereal crops such as rice, corn (maize), and wheat. Despite the vast diversity of their chromosome numbers and the DNA content of their genomes (Arumunganathan and Earle 1991), members of the Gramineae family show extensive genome conservation based on comparative genetic mapping using common DNA markers (Bennetzen and Freeling 1993; Gale and Devos 1998; Bennetzen 2000; Devos and Gale 2000; Keller and Feuillet 2000). Therefore, grasses have been considered a single genetic system (Bennetzen and Freeling 1993). With the discovery of massive retrotransposition in some large grass genomes, it was theorized that nested retrotransposition was the root cause of genome expansion, and that gene islands between seas of repetitive DNA were largely conserved (SanMiguel et al. 1996). However, recent data of genomic comparison at the DNA sequence level among grass species have shown many exceptions to the conservation of gene islands as well, resulting in the disruption of gene collinearity between closely related species (Bennetzen 2000; Devos and Gale 2000; Keller and Feuillet 2000). Exceptions to gene collinearity include microrearrangement or small-scale

'Present address: LPG-ATC, NCI Advanced Technology Center, 8717 Grovemont Circle, Gaithersburg, MD 20877, USA. ${ }^{2}$ Corresponding author.

E-MAIL messing@mbcl.rutgers.edu; FAX (732) 445-0072.

Article and publication are at http://www.genome.org/cgi/doi/10.1101/ gr.268302. Article published online before print in September 2002. genomic changes, such as gene insertion, deletion, duplication, or inversion (Bancroft 2000). In this study, we investigate additional causes of genome expansion besides retrotransposition, and how small-scale changes occurred during evolution.

We recently reported the characterization of a region of maize Chromosome 4S. This region contains DNA markers conserved among maize (2700 Mb; million base pairs), sorghum $(770 \mathrm{Mb}$ ), and rice $(430 \mathrm{Mb}$; Arumunganathan and Earle 1991). In maize this region contains a large storageprotein gene family, the $22-\mathrm{kD}$ zein gene family, with 23 members (Song et al. 2001). Interestingly, 22 members are tandemly arrayed within $168 \mathrm{~kb}$, whereas one copy is located $20 \mathrm{cM}$ closer to the centromere of maize Chromosome 4S. Sorghum also has a storage protein, 22-kD kafirin, homologous to the maize 22-kD zein (DeRose et al. 1989). Rice does not have a corresponding storage protein (Kim and Okita 1988). Phylogenetic analysis of the $22-\mathrm{kD}$ zein gene family indicates that most of the copies arose from gene amplification after maize and sorghum diverged (Song et al. 2001). It would be interesting to see how such a large gene cluster could contribute to genomic expansion in this region, and how active gene amplification in the past could have affected the flanking orthologous sequences. Therefore, we isolated and sequenced the orthologous regions corresponding to the maize 22-kD zein cluster region from two other closely related species: rice and sorghum. In rice, the orthologous regions from two different subspecies, Oryza sativa L. ssp. japonica and Oryza sativa L. ssp. indica, were characterized. These two sub- 
species separated <1 mya (Bennetzen 2000); sorghum and maize separated from each other $\sim 16.5$ mya (Gaut and Doebley 1997); and rice separated from the ancestor of sorghum and maize $\sim 50$ mya (Kellogg 2000). The sequences from $j a-$ ponica and indica could indicate how sequence divergence initiated, whereas those sequences from sorghum and maize could indicate how sequence divergence accumulated during a long evolutionary period. By comparing these orthologous regions, we gained insight on how genome structure evolved.

\section{RESULTS}

\section{Isolation of Orthologous Regions}

We previously sequenced a $346-\mathrm{kb}$ maize genomic region that contained the $22-\mathrm{kD} \alpha$-zein storage protein gene family (Song et al. 2001). This region is linked to the maize RFLP marker php200725, a gene of unknown function that is conserved among maize, rice, and sorghum (data not shown). Using this marker, two rice BAC (bacterial artificial chromosome) clones were selected from BAC libraries of the rice subspecies japonica and indica. Although these rice BAC clones have a rather small insert size (77 kb and $70 \mathrm{~kb}$, respectively), we have determined that they comprise a region larger than the entire $346-\mathrm{kb}$ maize region, exemplifying the expansion of the large maize genome versus the small rice genome. To maximize alignments between rice and maize, the maize contig was extended by selecting another BAC clone from the same maize BAC library overlapping with its $3^{\prime}$ end. This yielded a total of 435 $\mathrm{kb}$ from maize, of which $380 \mathrm{~kb}$ was suitable for alignment

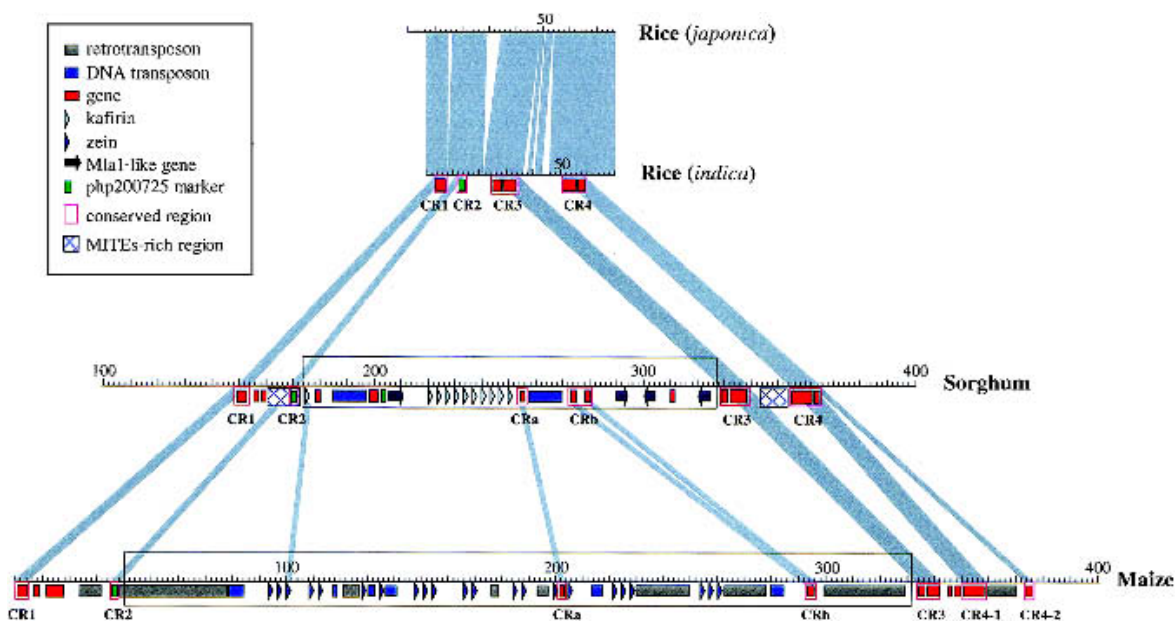

Figure 1 Sequence comparison of orthologous regions from rice, sorghum, and maize. Sequences of genomic regions from rice (subspecies japonica and indica), sorghum, and maize have been vertically arranged with a size ruler (in kilobases) for each sequence. Only orthologous regions (CR1-CR4) are highlighted. Light-blue areas indicate the homologous regions. The boxed sections between CR2 and CR3 in sorghum and maize represent an insertion relative to rice. Pink boxes along the rulers indicate conserved sequence regions across species (CR1-CR4, CRa, CRb). In maize, CR4 was divided into CR4-1 and CR4-2, reflecting an insertion relative to sorghum and rice. In sorghum, CRb was split into two pieces because of an insertion relative to maize. Green bars indicate RFLP marker php200725 and its orthologs. The second green bar in the sorghum region marks the duplication of php200725. Small triangles indicate amplified storage-protein gene copies and their orientation (22-kD zein in maize and 22-kD kafirin in sorghum, respectively). Violet arrows indicate Mla1-like disease-resistance genes and their orientation. All other genes are indicated by small red bars. Genes without a pink outer box indicate nonconserved genes. Gray bars indicate areas of retrotransposons, and blue bars DNA transposons. Two hatched boxes in sorghum indicate two MITE-rich regions ( $5^{\prime}$ region, $<1 \mathrm{~kb} / \mathrm{MITE}$; $3^{\prime}$ region, <2 kb/MITE). All kafirins and zeins showed homology to each other, but only the oldest copies are indicated. A summary of predicted genes and their positions is given in Table 1 for convenience. with the rice inserts. Using sequence information from rice and maize, four BAC clones were selected from sorghum BAC libraries. These clones yielded a contig of $425 \mathrm{~kb}$. Only $220 \mathrm{~kb}$ was suitable for alignment with sequences from the other two

\section{Sequence Comparison of Orthologous Regions}

These orthologous regions around the php200725 marker (Fig. 1). Using rice as a reference, four CRs (conserved seFig. 1). The conserved marker $p h p 200725$ is part of CR2. These (1) regions contain either single genes (CR1 and CR2, was further divided by a retrotransposition between two genes. These conserved regions are separated by nonconserved sequences of various sizes. spacer does not contain any genes in rice, two genes and a

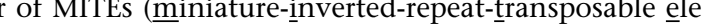
conserved genes and a retrotransposon in maize. The spacer between CR3 and CR4 shows very different characteristics. Its size is not proportional to genome size and varies even between the two rice subspecies. In rice, it differs by small reas simple sequence repeats (SSRs), but does not contain any genes. In sorghum, this spacer does not contain any genes, but multiple MITE sequences. In maize, although the size of the spacer is surprisingly shorter than in rice, it contains two genes.

The largest expansion of sorghum $(\sim 155 \mathrm{~kb})$ and maize $(\sim 290$ $\mathrm{kb})$ relative to rice occurs between CR2 and CR3 (boxed sections in Fig. 1). In sorghum, the expansion is comprised of three amplified genes, fragments of two DNA transposable elements, and five other genes, but no retrotransposons. The most extensive gene amplification is that of a storage-protein gene, 22$\mathrm{kD} \alpha$-kafirin, with 11 copies, all with the same orientation, and 10 forming a nearly perfect tandem array with a unit size of $3290 \mathrm{bp}$. We found that the second amplified gene, a putative Mla1-like disease resistance gene (Halterman et al. 2001), has four copies, but they are not in tandem. The third amplified gene is the php200725 ortholog, with two tandem copies.

The corresponding expansion in maize is attributed to a combination of gene amplification and retrotransposition. Only the storageprotein gene that is orthologous to 
Table 1. Genes in Orthologous Regions

\begin{tabular}{|c|c|c|c|c|c|c|}
\hline Gene & & Rice (japonica) & Rice (indica) & Sorghum & Maize & Designation \\
\hline 1 & CR1 & $9366-14262(+)$ & $2846-7670(+)$ & $148946-154211(+)$ & $189-4312(+)$ & Conserved unknown gene \\
\hline 2 & & & & 156139-157293(+) & & Glutathione transferase \\
\hline 3 & & & & 157758-159936(-) & & Unknown gene \\
\hline 4 & & & & & $6462-8850(+)$ & Putative transporter \\
\hline 5 & & & & & 11192-18668(+) & Plastid division protein \\
\hline 6 & CR2 & $19445-22363(+)$ & $11475-14354(+)$ & 169053-171854(+) & $36233-37925(+)$ & php200725 marker, unknown gene \\
\hline 7 & & & & $175829-176626(+)^{a}$ & & First copy of 22-kD kafirin \\
\hline 8 & & & & & $93984-94784(+)^{a}$ & First copy of 22-kD zein \\
\hline 9 & & & & $178451-180151(-)$ & & Fatty acid elongase \\
\hline 10 & & & & $197864-200950(+)$ & & Receptor kinase \\
\hline 11 & & & & $202842-203560(+)$ & & Duplicated php200725 copy \\
\hline 12 & & & & 206881-212502(+) & & Mla1-like disease-resistance gene \\
\hline 13 & & & & $250052-250858(+)^{a}$ & & Last copy of 22-kD kafirin \\
\hline 14 & $\mathrm{CRa}$ & & & $255469-256047(+)$ & 202981-203565(+) & Disease response gene \\
\hline 15 & & & & & $261759-262472(+)^{a}$ & Last copy of 22-kD zein \\
\hline 16 & $\mathrm{CRb}$ & & & $272671-279846(+)$ & 293515-295648(+) & Cytochrome P450 \\
\hline 17 & & & & 290165-293582(+) & & Mla1-like disease-resistance gene \\
\hline 18 & & & & $300318-303679(-)$ & & Mla1-like disease-resistance gene \\
\hline 19 & & & & $315276-316808(-)$ & & UTP-glucosyl transferase \\
\hline 20 & & & & $321692-325061(-)$ & & Mla1-like disease-resistance gene \\
\hline 21 & CR3 & $38828-41539(-)$ & $25162-27849(-)$ & $329439-331608(-)$ & $334124-336230(-)$ & Receptor kinase \\
\hline 22 & CR3 & $42745-47961(-)$ & $28725-34455(-)$ & $332518-338050(-)$ & 337394-341159(-) & Sugar transporter \\
\hline 23 & & & & & $345917-346886(-)$ & Cytidine deaminase \\
\hline 24 & & & & & $347494-349825(+)$ & Ribosomal protein (S12) \\
\hline 25 & CR4 & $57473-62798(+)$ & $50047-55354(+)$ & 354923-361633(+) & 350586-358453(+) & RNA-binding protein \\
\hline 26 & CR4 & $64338-66962(+)$ & $56888-59512(+)$ & $362635-364102(+)$ & $373678-376578(+)$ & Peptidase-S26 \\
\hline
\end{tabular}

Numbers indicate start and end positions of predicted genes: $(+)$ or $(-)$ refer to the transcriptional direction of the predicted genes.

${ }^{\mathrm{a}}$ Only the first and last copies of the amplified 22-kD storage-protein gene are indicated here. See Fig. 1 for the relative positions of other copies.

sorghum was amplified, resulting in 22 tandem copies of the $22-\mathrm{kD} \alpha$-zein gene. This tandem array of zein genes is interrupted by transposable elements and other genes spread over $168 \mathrm{~kb}$. The entire expansion consists of several DNA transposable elements (blue bars in Fig. 1) and $110 \mathrm{~kb}$ of retrotransposons (gray bars), as well as two other genes, one in the middle and the other downstream of the zein cluster, which are conserved between maize and sorghum (CRa and CRb, Fig. 1).

Within the orthologous regions (CR1-CR4), rice has six genes; sorghum has 15 different genes, of which three have been amplified, resulting in a total of 29 genes; and maize has 13 different genes, of which one has been amplified, resulting in a total of 34 genes. Although gene amplification has caused a large sequence expansion, it is remarkable that the amplified copies in maize and sorghum are confined and do not disrupt the order and orientation of nonamplified conserved genes, such as CRa and CRb (Fig. 1). As a result, gene amplification increased local gene density of the respective genome (in CR1-CR4, rice, 1 gene/9.5 kb; sorghum, 1 gene/7.4 kb; maize, 1 gene/11 kb).

\section{Analysis of Paralogous Sequences}

A major finding of this study is the presence of different genes in nonconserved sequences of the sorghum and maize php200725 regions (Table 1). Although these genes are missing from the rice php200725 region, based on sequence and hybridization data, in many cases copies of these genes are present in the rice genome, but mapped to nonorthologous chromosomal locations (Table 2). One exception is the $22-\mathrm{kD}$ storage-protein gene, which does not have a homologous sequence in the rice genome. We also found at least four genes that are not only in a nonorthologous position, but also am- plified at the same time. A single putative receptor kinase in the sorghum region (gene 10, Tables 1 and 2) has 10 clustered homologs in a single BAC clone on rice Chromosome 4 . Also in the sorghum region, a single putative glucosyl transferase gene (gene 19, Tables 1 and 2) has four clustered homologs on rice Chromosome 1. These clustered gene copies are apparently derived from gene amplification. The Mla1-like disease resistance gene that is amplified in sorghum in the php200725 region has a single homologous copy on rice Chromosome 1. $\mathrm{CRa}$, which encodes a putative disease response gene and is orthologous between maize and sorghum, is positioned on the other arm of rice Chromosome 11, $65 \mathrm{cM}$ away from the rice $p h p 200725$ region. The rice CRa is also amplified in contrast to maize and sorghum (see Methods). These data strongly suggest that gene amplification and gene movement are functionally associated with each other.

Additional conserved sequences could be found within extra sequences $3^{\prime}$ to CR4 from rice and sorghum (data not shown), including a predicted gene consisting of conserved MATH/TRAF and BTB/POZ domains (Albagli et al. 1995; Uren and Vaux 1996). In addition to the orthologous position in the php200725 region of rice on Chromosome 11, a large number of paralogous sequences of this gene were found at the central portion of rice Chromosome 10. We sequenced $\sim 2.9 \mathrm{Mb}$ surrounding these gene copies. Subsequent sequence analysis revealed a total of 48 copies of this gene, with 36 gene copies clustered within a 330-kb region, 9 copies clustered within another $85-\mathrm{kb}$ region, and 3 other copies scattered elsewhere. Further analysis of the same region provided several other examples of gene amplification, including 27 copies of a glycine-rich protein within $230 \mathrm{~kb}$ (Table 3). Of a total of 360 predicted genes within this region, $\sim 26 \%$ were the result of gene amplification. Given a gene density of $8 \mathrm{~kb} /$ gene 
Table 2. Rice Homologous Genes of Nonconserved Genes From php200725 Regions

\begin{tabular}{|c|c|c|c|c|c|c|}
\hline Gene $^{a}$ & & Map position & Clone \# & GenBank \# & Description of homologous gene & $e$-value ${ }^{b}$ \\
\hline 2 & & $\mathrm{ch} 1: 20.2 \mathrm{cM}$ & BAC OJ1174_D05 & AP003118 & Hypothetical protein & $1 e-28$ \\
\hline 3 & & ch10: $72.6 \mathrm{cM}$ & OSJNBa0027P10 & AC084763 & Hypothetical protein & $3 e-50$ \\
\hline 4 & & ch10: $58.9 \mathrm{cM}$ & OSJNBb0018B10 & AC051634 & Putative transporter & e-102 \\
\hline 5 & & ch4: $122.9 \mathrm{cM}$ & OSJNBa0087O24 & AL606646 & Plastid division protein FtsZ & $6 e-68$ \\
\hline 9 & & ch10: $6.8 \mathrm{cM}$ & OSJNBa0036D19 & AC087723 & Putative senescence-associated protein 15 & e-127 \\
\hline 10 & & ch4: $111.0-111.3 \mathrm{cM}$ & OSJNBa0043L09 & AL606444 & Putative receptor kinase & $9 e-65$ \\
\hline 12 & & $\mathrm{ch} 1: 98.5 \mathrm{cM}$ & PAC P0681B11 & AP003022 & Mla1-like disease-resistance gene & $7 e-116$ \\
\hline $14^{\mathrm{c}}$ & $\mathrm{CRa}$ & ch11: $30.5-32.1 \mathrm{cM}$ & OSJNBa0034004 & $\mathrm{N} / \mathrm{A}$ & Disease response gene & $\mathrm{N} / \mathrm{A}$ \\
\hline 16 & $\mathrm{CRb}$ & ch1: $26.8-28.4 \mathrm{cM}$ & PAC P0419B01 & AP003244 & Cytochrome $\mathrm{P} 450$-like protein & $6 e-40$ \\
\hline 17 & & ch1: $98.5 \mathrm{cM}$ & PAC P0681B11 & AP003022 & Mla1-like disease-resistance gene & e-131 \\
\hline 18 & & ch1: $98.5 \mathrm{cM}$ & PAC P0681B11 & AP003022 & Mla1-like disease-resistance gene & e-154 \\
\hline 19 & & ch1: $16.1-19.9 \mathrm{cM}$ & PAC P0013F10 & AP002523 & Putative glucosyl transferase & $5 e-75$ \\
\hline 20 & & ch1: $98.5 \mathrm{cM}$ & PAC P0681B11 & AP003022 & Mla1-like disease-resistance gene & e-147 \\
\hline
\end{tabular}

a Numbers correspond to those in Table 1.

${ }^{b} e$-value is based on nucleotide sequence level similarity.

Information in this row comes from experimental data (see Methods).

within the $3-\mathrm{Mb}$ region, one would predict a total of 49,000 genes for the rice genome. Discounting the amplified gene copies, this number would be only 36,000 . Therefore, it appears that gene amplification contributes to a large proportion of genome size.

\section{DISCUSSION}

\section{Contiguous Genomic Sequences From Large Plant Genomes}

BAC libraries from three grass species, maize, sorghum, and rice, have been used to clone orthologous sequences based on conserved gene sequences. With a small genome such as rice, a single BAC clone was sufficient to comprise all aligned markers. However, with larger genomes like sorghum and maize, contiguous and overlapping BAC clones had to be isolated. The absence of STC (sequence tagged connector) and FPC (finger printing contig) databases (see Methods) for the
BAC libraries from maize and sorghum has slowed the effort to obtain contiguous sequence information. The sequencing of $2.9 \mathrm{Mb}$ of the central portion of rice Chromosome 10, on the other hand, has been greatly facilitated by the rice STC and FPC resources (Mao et al. 2000). Once these resources become available for maize and sorghum, additional comparison analysis among these three species will be simplified. For now, the two contiguous sequences from maize and sorghum described here provide us with the greatest amount of contiguous-sequence information of both genomes.

\section{Mosaic Organization of Orthologous Sequences}

In this study we observed a mosaic organization of evolutionarily conserved (orthologous) sequences across the php200725 regions among rice, maize, and sorghum. The distinct feature of such an organization is that conserved sequences were interspersed with nonconserved sequences. This mosaic structure is apparent only between sufficiently diverged species. For example, between the two subspecies of rice, sequence divergence is not sufficient to uncover such a mosaic structure, whereas the mosaic structure is quite apparent in the other pairwise or triple comparisons. Besides sequence divergence, large regions are also required to visualize a mosaic structure. The sequence should be long enough to cover several conserved islands separated by nonconserved seas. This is particularly challenging when dealing with a large, complex genome like maize for two main reasons. First, it is common for conserved gene islands to be separated by a long stretch of nonconserved sequences. Secondly, many repetitive sequences usually contain nested retrotransposons, further complicating the analysis. In this study, the nonconserved regions in between 
conserved sequences could be as long as $155 \mathrm{~kb}$, as in the sorghum region, or $290 \mathrm{~kb}$ as in the maize region.

Between sufficiently diverged species, the conserved regions usually only contain genes, whereas the nonconserved regions contain a mixture of genes, transposable elements, and other diverged sequences. However, it is surprising to see so many genes present in nonconserved regions in this study. These genes must have originated from different positions in the genome. This indicates that gene movement must have been quite frequent.

\section{Gene Amplification and Gene Movement}

How can genes move between different genomic positions? This study suggests a possible mechanism of gene movement that is associated with gene amplification. Besides examples provided in this study, gene movement associated with gene amplification has also been documented in other studies. For example, the floury-2 locus in maize is one copy of the amplified $22-\mathrm{kD}$ zein gene translocated $20 \mathrm{cM}$ away from other copies (Song et al. 2001). The adh1 locus in maize and sorghum is a translocated copy from one of the two duplicated genes (Tikhonov et al. 1999; Tarchini et al. 2000). Therefore, one can envision a mechanism by which gene amplification generates free gene copies that could be inserted elsewhere in the genome by illegitimate recombination. Such a mechanism is reminiscent of plant DNA transformation by direct DNA uptake, or the particle bombardment method in which free DNA gets inserted by illegitimate recombination (Krens et al. 1982; Klein et al. 1988). On the other hand, gene copies translocated to nonorthologous positions are also prone to amplification, like the Mla1-like gene in the sorghum region, or the extreme amplification of the gene containing MATH/ TRAF and BTB/POZ domains at the nonorthologous 2.9-Mb region in rice. The association of gene amplification with gene translocation could quickly generate divergent sequences in certain regions of the genome, and it might also underlie the rapid reorganization of resistance gene homologs in grass genomes (Leister et al. 1998).

\section{Formation of Mosaic Organization by Hotspots Expansion}

In this study, we were able to analyze sequences with different degrees of divergence. The sequences from the two rice subspecies diverged separately for $<1$ mya (Bennetzen 2000). The conserved sequence regions are also comprised of genes, but they extend into intergenic regions, leaving rather narrow nonconserved regions (Fig. 1, light-blue areas). These regions consist of a mixture of short repeat sequences and mobile elements. However, these elements appear to be defective elements rather than the result of homologous recombination of LTRs. Solo LTRs could indicate a reversal of genome expansion, which, however, does not appear to be the case in the rice php200725 region, because defective elements could transpose without further truncations. Interestingly, the position of these narrow nonconserved regions aligns with those in sorghum and maize, where more significant changes occurred. Sorghum and maize provide sequences that diverged 16.5 mya (Gaut and Doebley 1997). We found three more genes not present in rice, but conserved between sorghum and maize. Almost all other changes occurred after maize and sorghum separated. The three extra conserved genes are the oldest copy of the $22-\mathrm{kD}$ storage protein $(22-\mathrm{kD}$ zein and kafirin were amplified after sorghum and maize separated), CRa and CRb (Fig. 1). During this 16.5-million-year period, extensive gene movement and amplifications occurred. In addition, whereas massive retrotransposition occurred in maize, sorghum had extensive MITEs insertion. It is remarkable that gene amplification, retrotransposition, and MITEs insertions are all confined within a restricted space, promoting the formation of clustered gene families, nested transposons, and MITE-rich regions. Conserved sequence regions were further diminished at the same time, and only gene sequences or the exons of genes were conserved. Furthermore, rice and sorghum or rice and maize sequences diverged nearly 50 mya. Except for the changes to the three conserved genes between CR2 and CR3, other changes were either already saturated or difficult to detect on top of the changes that occurred within 16.5 million years.

Therefore, we believe that when orthologous sequences were just starting to diverge, small nonconserved regions formed in intergenic regions. These nonconserved regions formed hotspots for further sequence divergence. Orthologous sequences further diverged by expanding from these hotspots to form larger nonconserved regions. Such expansion occurred by accumulating small-scale changes, such as gene movement, gene amplification, and transposition (Bancroft 2000). Because all the changes were confined within or between the hotspots regions, we can predict that gene amplification could form gene family clusters (The Arabidopsis Genome Initiative 2000; Song et al. 2001); retrotranspositions could form nested retrotransposon regions (SanMiguel et al. 1996); and MITE transpositions form MITE-rich regions (Jang and Wessler 2001), and so on. Genes from one hotspot might move to another hotspot owing to their active status, translocating new genes into a different nonconserved region. The genes newly moved into a new hotspot might continue to undergo further small-scale changes, such as gene amplification. In addition, conserved regions and nonconserved regions could also change their state. Hotspots could turn cold by switching a nonconserved region into a conserved region. As an example, $\mathrm{CRa}$ and $\mathrm{CRb}$ within sorghum and maize regions, as compared with rice, were once nonconserved sequences. Even before sorghum and maize separated, CRa and CRb turned into conserved sequences. Reciprocally, conserved regions also could switch to nonconserved regions, for example, the $22-\mathrm{kD}$ zein and kafirin genes, whose oldest copies were conserved sequences between maize and sorghum. After maize and sorghum separated, both of them turned into hotspots for gene amplification, and turned conserved sequences into nonconserved sequences.

Differential divergence of these nonconserved hotspots along chromosomes is then manifested during speciation, and a mosaic of conserved segments interspersed with nonconserved segments becomes apparent in the comparison of orthologous regions of different species.

\section{Do Grass Genomes Have a Faster Evolutionary Clock?}

Mammalian genomes, which diverged much earlier (100 mya) than the grass genomes described here (50 mya; Burt et al. 1999; Kellogg 2000), also contain rapidly changing nonorthologous sequences (Chiaromonte et al. 2001), although not to the same degree as in this case. In grasses, even between much more closely related species such as sorghum and maize, the sequence divergence could be very drastic. It ap- 
pears that grass genomes may have evolved much more rapidly than one would have predicted by only comparing coding sequence substitution rates (Gaut et al. 1996) or chromosome structural mutation rates (Paterson et al. 1996). Because polyploidization and segmental chromosomal duplication occur on top of gene amplification in many higher plants (Vision et al. 2000; Gaut 2001), the number of their paralogous sequences exceeds those of other eukaryotic organisms sequenced so far, including the human genome (Messing 2001). Such a fast evolutionary clock might also explain the great success of speciation of certain large families, such as Gramineae.

\section{METHODS}

\section{BAC Clone Isolation and Sequencing}

Maize RFLP marker php200725, which is conserved among maize, rice, and sorghum, was used to isolate two rice BAC clones from BAC libraries of two rice subspecies japonica (Oryza sativa japonica cv. Lemont) and indica (Oryza sativa indica cv. Teqing), available from Clemson University Genome Institute (CUGI). Clone 1H19 from the japonica Lemont library and clone $16 \mathrm{~F} 19$ from the indica Teqing library were sequenced.

Previously we sequenced a 346-kb maize region (Song et al. 2001). To maximize alignments between rice and maize, an additional BAC clone (BAC \#072) from the same maize BAC library (Zea mays cv BSSS53; Song et al. 2001) was selected, which extended the maize $346-\mathrm{kb}$ contig from the 3 '-end.

Using sequence information from rice and maize, BAC clones containing orthologous sequences were selected from two sorghum BAC libraries. BAC clones SB25M18 and SB40L16 came from Sorghum bicolor cv BTx623, digested with HindIII and BamHI, respectively, available from the Texas A\&M BAC Center. BAC clones SB126P21 and SB234M12 came from the Sorghum bicolor cv BTx623 HindIII library, available from CUGI.

A minimum-tiling path based on end-sequence information and using sequence-tagged connectors (STCs), was used to select neighboring BAC clones (Mao et al. 2000). A total of 22 clones yielded a complete contiguous sequence of $2,883,802$ bp that spans $12 \mathrm{cM}$ on rice Chromosome 10 , spanning between markers $S 11069$ at position $29.8 \mathrm{cM}$ and C1286 at position $41.8 \mathrm{cM}$ of the Oryza sative japonica cv. Nipponbare map from the Rice Genome Research Program (RGP) in Japan (Rice Genome Research Program in Japan, 2001; http://rgp. dna.affrc.go.jp/).

All BAC clones were sequenced by the shotgun DNA sequencing method (Messing et al. 1981) using sequence mates of pUC-based templates (Vieira and Messing 1982) as described before (Song et al. 2001).

\section{Sequence Analysis}

We performed homology searching using BLAST2 (http:// www.ncbi.nlm.nih.gov/blast/ bl2seq/bl2.html; Tatusova and Madden 1999). Gene prediction was based on both GeneScan (http://genes.mit.edu/Genscan.html) and FGENESH++ (http://www.softberry.com./berry.phtml?topic=gfind). Protein sequences generated from gene prediction programs were used to search the protein database (Altschul et al. 1997). Expressed sequence tag (EST) database searches were used to improve the prediction of expressed genes. Transfer RNA (tRNA) was predicted using the tRNA-scan-SE program (http:// www.genetics.wustl.edu/eddy/tRNAscan-SE/). RepeatMasker (http://repeatmasker.genome.washington.edu/cgi-bin/ RepeatMasker) was used to screen interspersed repeats and low-complexity DNA sequences.

\section{Rice BAC Clone Fingerprint Contig (FPC) Analysis}

Rice BAC filters (Oryza sative japonica cv. Nipponbare, HindIII section) from the International Rice Genome Sequencing Project (IRGSP) were used to screen positive clones containing the putative disease-resistance response gene (CRa in Fig. 1). These clones have been assembled in Fingerprinting Contigs (FPCs) that have been anchored to the genetic map (http:// www.genome.clemson.edu/projects/rice/fpc/). Positives clones are within FPC \#206 on rice Chromosome 11, between markers $R 682(30.5 \mathrm{cM})$ and $R Z 316(32.1 \mathrm{cM})$, immediately adjacent to the rice Adh homologous region. The $p h p 200725$ ortholog falls within FPC \#256, also on Chromosome 11 but on the other side of the centromere, at position $97.4 \mathrm{cM}$. In addition, Southern blot analysis of these BAC clones detected multiple copies of this gene (data not shown), indicating that this gene became amplified in rice.

\section{ACKNOWLEDGMENTS}

We thank S. Kavchok and S. Young for technical assistance; J. Bennetzen of Purdue University, M. Vaudin, and B. Barbarzuk of Monsanto for critical reading of the manuscript. This work has been supported by DOE grant \#DE-FG05-95ER20194, USDA-NRI grant \#98-35300-6165, and NSF grant \#9975618 to J.M.

The publication costs of this article were defrayed in part by payment of page charges. This article must therefore be hereby marked "advertisement" in accordance with 18 USC section 1734 solely to indicate this fact.

\section{REFERENCES}

Albagli, O., Dhordain, P., Deweindt, C., Lecicq, G., and Leprince, D 1995. The BTB/POZ domain: A new protein-protein interaction motif common to DNA- and action-binding proteins. Cell Growth Differ. 6: 1193-1198.

Altschul, S.F., Madden, T.L., Schäffer, A.A., Zhang, J., Zhang, Z, Miller, W., and Lipman, D.J. 1997. Gapped BLAST and PSI-BLAST: A new generation of protein database search programs. Nucleic Acids Res. 25: 3389-3402.

The Arabidopsis Genome Initiative. 2000. Analysis of the genome sequence of the flowering plant Arabidopsis thaliana. Nature 408: 796-815.

Arumunganathan, K. and Earle, E.D. 1991. Nuclear DNA content of some important plant species. Plant Mol. Biol. Rep. 9: 208-219.

Bancroft, I. 2000. Insights into the structural and functional evolution of plant genomes afforded by the nucleotide sequences of Chromosomes 2 and 4 of Arabidoposis thaliana. Yeast 17: 1-5.

Bennetzen, J.L. 2000. Comparative sequence analysis of plant nuclear genomes: Microcolinearity and its many exceptions. Plant Cell 12: 1021-1029.

Bennetzen, J.L. and Freeling, M. 1993. Grasses as a single genetic system: Genome composition, colinearity and compatibility. Trends Genet. 9: 259-261.

Bureau, T.E. and Wessler, S.R. 1994. Mobile inverted-repeat elements of the Tourist family are associated with the genes of many cereal grasses. Proc. Natl. Acad. Sci. 91: 1411-1415.

Burt, D.W., Bruley, C., Dunn, I.C., Jones, C.T., Ramage, A., Law, A.S., Morrice, D.R., Paton, I.R., Smith, J., Windsor, D., et al. 1999. The dynamics of chromosome evolution in birds and mammals. Nature 402: 411-413.

Chiaromonte, F., Yang, S., Elnitski, L., Yap, V.B., Miller, W., and Hardison, R.C. 2001. Association between divergence and interspersed repeats in mammalian noncoding genomic DNA. Proc. Natl. Acad. Sci. 98: 14503-14508.

DeRose, R.T., Ma, D.P., Kwon, I.J., Hasmain, S.E., Klassy, R.C., and Hall, T.C. 1989. Characterization of the kafirin gene family from sorghum reveals extensive homology with zein from maize. Plant Mol. Biol. 12: 245-256.

Devos, K. and Gale, M.D. 2000. Genome relationships: The grass model in current research. Plant Cell 12: 637-646.

Gale, M.D. and Devos, K. 1998. Comparative genetics in the grasses. Proc. Natl. Acad. Sci. 95: 1971-1974.

Gaut, B.S. 2001. Patterns of chromosomal duplication in maize and their implications for comparative maps of the grasses. Genome Res. 11: 55-66. 
Gaut, B.S. and Doebley, J.F. 1997. DNA sequence information for the segmental allotetraploid origin of maize. Proc. Natl. Acad. Sci. 88: 2060-2064.

Gaut, B.S., Morton, B.R., McCaig, B.M., and Clegg, M.T. 1996. Substitution rate comparisons between grasses and palms: Synonymous rate differences at the nuclear gene Adh paralle rate differences at the plastid gene rbcL. Proc. Natl. Acad. Sci. 93: $10274-10279$

Halterman, D., Zhou, F., Wei, F., Wise, R.P., and Schulze-Lefert, P. 2001. The MLA6 coiled-coil, NBS-LRR protein confers AvrMla6-dependent resistance specificity to Blumeria graminis $\mathrm{f}$. sp. hordei in barley and wheat. Plant J. 25: 335-348.

Jang, N. and Wessler, S.R. 2001. Insertion preference of maize and rice miniature inverted repeat transposable elements as revealed by the analysis of nested elements. Plant Cell 13: 2553-2564.

Keller, B. and Feuillet, C. 2000 . Colinearity and gene density in grass genomes. Trends Plant Sci. 5: 246-251.

Kellogg, E.A. 2000. Evolutionary history of the grasses. Plant Physiol. 125: $1198-1205$.

Kim, W.T. and Okita, T.W. 1988. Structure, expression, and heterogeneity of the rice seed prolamines. Plant Physiol. 88: $649-655$.

Klein, T.M., Harper, E.C., Svab, Z., Sanford, J.C., Fromm, M.E., and Maliga, P. 1988. Stable genetic transformation of intact Nicotiana cells by the particle bombardment process. Proc. Natl. Acad. Sci. 85: 8502-8505.

Krens, F.A., Molendijk, L., Wullems, G.J., and Schilperoort, R.A. 1982. In vitro transformation of plant protoplasts with Ti-plasmid DNA. Nature 296: 72-74.

Leister, D., Kurth, J., Laurie, D.A., Yano, M., Sasaki, T., Devos, K., Graner, A., and Schulze-Lefert, P. 1998. Rapid reorganization of resistance gene homologues in cereal genomes. Proc. Natl. Acad. Sci. 95: 370-375.

Mao, L., Wood, T.C., Yu, Y., Budiman, M.A., Tomkins, J., Woo, S., Sasinowski, M., Presting, G., Frisch, D., Goff, S., et al. 2000. Rice transposable elements: A survey of 73,000 sequence-taggedconnectors. Genome Res. 7: 982-990.

Messing, J. 2001. Do plants have more genes than humans? Trends Plant Sci. 6: 195-196.

Messing, J., Crea, R., and Seeburg, P.H. 1981. A system for shotgun DNA sequencing. Nucleic Acids Res. 9: 309-321.

Paterson, A., Lan, T.H., Reischmann, K.P., Chang, C., Lin, Y.R., Liu, S.C., Burow, M.D., Kowalski, S.P., Katsar, C.S., DelMonte, T.A., et al. 1996. Toward a unified genetic map of higher plants, transcending the monocot-dicot divergence. Nat. Genet. 14: $380-382$.
SanMiguel, P., Tikhonov, A., Jin, Y.K., Motchoulskaia, N., Zakharov, D., Melake-Berhan, A., Springer, P.S., Edwards, K.J., Lee, M., Avramova, Z., et al. 1996. Nested retrotransposons in the intergenic regions of the maize genome. Science 274: 765-768.

Song, R., Llaca, V., Linton, E., and Messing, J. 2001. Sequence, regulation, and evolution of the maize $22-\mathrm{kD}$ zein gene family. Genome Res. 11: 1817-1825.

Tarchini, R., Biddle, P., Wineland, R., Tingy, S., and Rafalski, A. 2000 . The complete sequence of $340 \mathrm{~kb}$ of DNA around the rice Adh1-Adh2 region reveals interrupted colinearity with maize Chromosome 4. Plant Cell 12: 381-391.

Tatusova, T.A. and Madden, T.L. 1999. BLAST 2 sequences: A new tool for comparing protein and nucleotide sequences. FEMS Microbiol. Lett. 174: 247-250.

Tikhonov, A.P., SanMiguel, P.J., Nakajima, Y., Gorenstein, N.M. Bennetzen, J.L., and Avramova, Z. 1999. Colinearity and its exceptions in orthologous adh regions of maize and sorghum. Proc. Natl. Acad. Sci. 96: 7409-7414.

Uren, A.G. and Vaux, D.L. 1996. TRAF proteins and meprins share a conserved domain. Trends Biochem. Sci. 21: 244-245.

Vieira, J. and Messing, J. 1982. The pUC plasmids, an M13mp7 derived system for insertion mutagenesis and sequencing with synthetic universal primers. Gene 19: 259-268.

Vision, T.J., Brown, D.G., and Tanksley, S.D. 2000. The origins of genomic duplications in Arabidopsis. Science 295: 2114-2117.

\section{WEB SITE REFERENCES}

http://genes.mit.edu/GENSCAN.html; the new Genscan Web server at MIT.

http://repeatmasker.genome.washington.edu/cgi-bin/RepeatMasker; RepeatMasker Web server.

http://rgp.dna.affrc.go.jp/; Rice Genome Research Programe.

http://www.genetics.wustl.edu/eddy/tRNAscan-SE; tRNAscan-SE Search server.

http://www.genome.clemson.edu/projects/rice/fpc; Rice FPC map. http://www.ncbi.nlm.nih.gov/blast/bl2seq/bl2.html; NCBI BLAST2 Web server.

http://www.softberry.com./berry.phtml?topic=gfind; Softberry Gene Finding Web page, FGENESH++.

Received March 11, 2002; accepted in revised form July 25, 2002. 


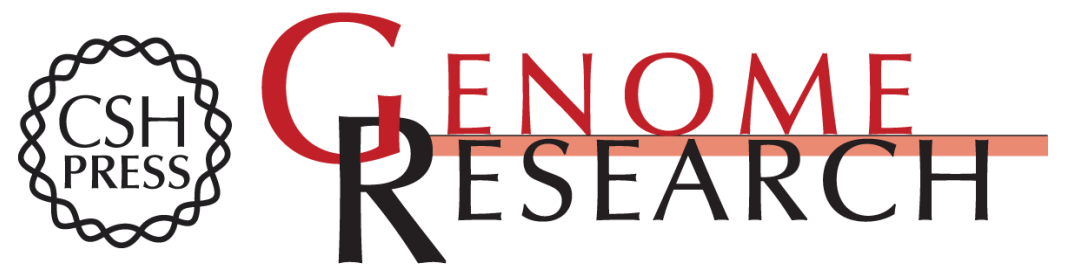

\section{Mosaic Organization of Orthologous Sequences in Grass Genomes}

Rentao Song, Victor Llaca and Joachim Messing

Genome Res. 2002 12: 1549-1555

Access the most recent version at doi:10.1101/gr.268302

References This article cites 33 articles, 18 of which can be accessed free at:

http://genome.cshlp.org/content/12/10/1549.full.html\#ref-list-1

\section{License}

Email Alerting Receive free email alerts when new articles cite this article - sign up in the box at the Service top right corner of the article or click here.

\section{Affordable, Accurate Sequencing.}

To subscribe to Genome Research go to: https://genome.cshlp.org/subscriptions 